\title{
BMY21190, A Potent Inhibitor of cAMP Phosphodiesterase
}

\author{
Masaru Minami, Masahiko Hirafuji, *Edward M. Driscoll, and \\ *Benedict R. Lucchesi \\ Department of Pharmacology, Faculty of Pharmaceutical Sciences, Health Sciences University \\ of Hokkaido, Hokkaido, Japan; and *Department of Pharmacology, University of Michigan \\ Medical School, Ann Arbor, Michigan, USA
}

Key Words: Antithrombotic action-BMY21190-cAMP phosphodiesterase inhibitor-Canine occlusion-reperfusion model-Infarct size-Myeloperoxidase activity.

\section{INTRODUCTION}

A number of compounds capable of inhibiting the aggregation of blood platelets have been reported in recent years. Synthesized compounds containing the imidazo [4,5-b] quinoline-2-one nucleus are a new series of structurally-novel inhibitors of platelet aggregation (38). These compounds are potent broad-spectrum inhibitors that inhibit platelet aggregation caused by thrombin, ADP, and collagen with roughly equal potency $(8,15)$. BMY21190 (Fig. 1) inhibits ADP- and collagen-induced aggregation of rabbit platelets with an efficacy comparable to prostacyclin (38). BMY21190 may also be capable of elevating the cAMP levels within platelets sufficiently to activate the cAMP-dependent protein kinase as does BMY20844 (60, Fig. 1). The active catalytic subunit is released by the binding of cAMP to the regulatory subunit of the protein kinase and then acts at many different steps in the biochemical pathways to inhibit platelet inhibition $(13,58,59)$. Agents that elevate platelet cAMP levels, including inhibitors of platelet cAMP phosphodiesterase (PDE) $(2,23,38,46,65)$, are known to inhibit platelet aggregation $(21,38$, 40). Platelet aggregation is generally regarded as an important event in the initiation of arterial thrombosis. The current interest in inhibitors of cAMP-PDE as therapeutic agents has largely arisen from the recognition that there are distinct PDE isozyme families and that tissues have different complements of isozymes.

Nomenclature and subcellular localization of cAMP-PDE isozymes are to be found in articles from Beavo's $(4,28)$ and Weishaar's laboratories $(67,68)$. BMY20844 and BMY21190 have the characteristics of selective type III inhibitors of "low Km" one of which is high affinity for cAMP (38). The cAMP-PDE type III isozyme has been isolated from or found in platelets $(17,46)$, cytosolic fractions of bovine cardiac tissue (19), and

Address correspondence and reprint requests to Dr. M. Minami at Department of Pharmacy, Faculty of Pharmaceutical Sciences, Health Sciences University of Hokkaido, Ishikari-Tobetsu, Hokkaido 061-02, Japan. 


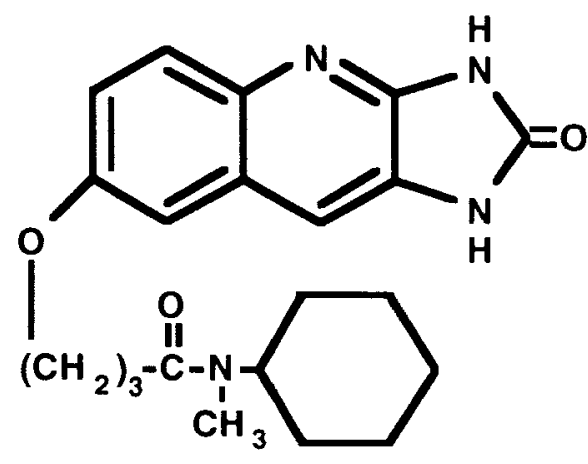

BMY 21190

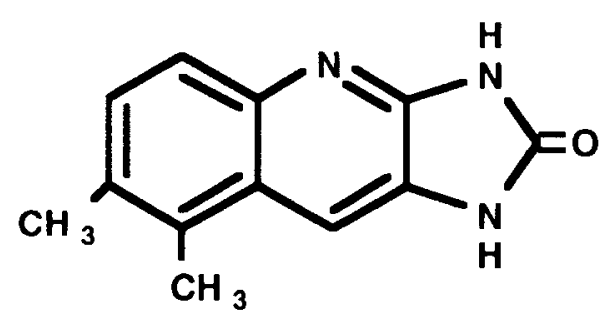

FIG. 1. The chemical structures of BMY20844 and BMY21190.

sarcoplasmic reticulum of canine heart muscle (30). This enzyme is also similar to the membrane-bound PDE in adipocytes $(9)$, liver $(73)$, and smooth muscle $(36,69)$. The type III cAMP-PDE isozyme in the heart is the target of a number of agents that cause an increase in contractile force $(18,24)$ and a decrease in peripheral vascular resistance in addition to inhibition of platelet aggregation (41).

The bipyridine cardiotonics, amrinone and milrinone, also inhibit cAMP-PDE (type III) and thereby the platelet aggregation. Studies in vitro and in vivo with amrinone have demonstrated impaired thromboxane $\mathrm{A}_{2}$ formation $(31,51,52,66)$. Aspirin and dipyridamole are not broad-spectrum inhibitors of aggregation. Anagrelide was a very promising candidate until its thrombocytopenic action was observed (1). Thus, in an attempt to develop other compounds possessing a favorable pharmacological profile, but lacking thrombocytopenic side effects, a series of related imidazoquinolines has been synthesized. While milrinone, a selective inhibitor of low $\mathrm{Km}$ cAMP-PDE, is a potent cardiac stimulant it did not produce thrombocytopenia in humans suggesting that the side effect was not related to inhibition of low Km cAMP-PDE (3). BMY21190 has a coronary vasodilating effect. There are no reports available with respect to the hemodynamic action of BMY21190. It was evaluated for its ability to modify the development of experimental thrombosis resulting from anodal current injury ( $100 \mu \mathrm{A}$ for $6 \mathrm{hr})$ of the intimal surface of the left circumflex coronary artery (LCX) in anesthetized dogs (42). This review also summarizes the effect of BMY21190 on infarct size in a canine ischemic model that underwent a 90-min occlusion and 6-hr reperfusion of the left coronary artery (43).

\section{CHEMISTRY}

BMY20844 (1,3-dihydro-7,8-dimethyl-2H-imidazo [4,5-b] quinolin-2-one) and one of its derivatives, BMY21190 (7-[4-(N-cyclohexyl-N-methylamino)-4-oxobutoxy]-1,3dihydro-2H-imidazo [4,5-b] quinolin-2-one) (Fig. 1) were synthesized by the BristolMyers Cardiovascular Chemistry Group, Wallingford, CT, USA. Compounds containing the imidazo [4,5-b] quinolin-2-one tricyclic nucleus are a new class of potent broadspectrum inhibitors of platelet aggregation (40). These compounds are very insoluble in 
water. The ring system of the imidazolin-2-one also exhibits a potent intrinsic activity that can be improved by introduction of substituents to the benzene ring. BMY20844, the prototype of these compounds, was identified as a promising clinical candidate due to its in vitro and in vivo potency for inhibition of platelet aggregation similar to analgrelide (40). Oral doses of BMY20844 provided protection similar to that of analgrelide in animal models of thrombosis. They produced, however, milder inodilating effects. BMY20844 is associated with much milder increases in ventricular contractile force and heart rate and with reductions in blood pressure in anesthetized ferrets and dogs (38). Rabbit heart cAMP-PDE isozymes were resolved by ion-exchange chromatography. BMY20844 inhibited only type III (a cGMP-inhibitable, low Km, cAMP-specific PDE) with an $\mathrm{IC}_{50}$ value of $5 \times 10^{-8} M(60)$. BMY20844 also inhibited canine cardiac sarcoplasmic reticulum membrane-bound cGMP-inhibitable, low $\mathrm{Km}$, cAMP-specific PDE with virtually the same potency as the inhibition of CAMP-PDE in the platelet homogenate (60). In washed platelets, BMY20844 elevated cAMP levels and activated the platelet CAMPdependent protein kinase. Introduction of functionalized side chains to this nucleus also markedly enhances biological activity, and BMY21190 inhibits ADP- and collageninduced platelet aggregation in vitro with potency comparable to prostacyclin ( $\mathrm{IC}_{50}$ values of $1-3 \mathrm{ng} / \mathrm{ml}$ ). This compound has also been found to be a powerful inodilating agent following oral administration in dogs and ferrets, and has prompted a search for potent antithrombotic agents of this basic chemical structure (40).

\section{ANTITHROMBOTIC EFFECTS OF BMY21190}

\section{Low Amperage Electrical Stimulation of Canine LCX Coronary Artery}

BMY21190 was evaluated for its ability to modify the development of experimental thrombosis resulting from anodal current injury $(100 \mu \mathrm{A}$ for $6 \mathrm{hr})$ of the intimal surface of the left circumflex coronary artery (LCX) in anesthetized dogs (42). As shown in Fig. 2 , distal to the arterial branch and proximal to its first descending branch, $1-2 \mathrm{~cm}$ of the LCX was isolated from the surrounding tissue by careful blunt dissection. Within this isolated region, an electromagnetic flow probe was affixed to the artery for the continuous measurement of LCX blood flow. To aid in the insertion of the LCX-stimulating electrode, the tip of a 25-gauge hypodermic needle was attached to a 28-gauge teflon-coated silver wire. This electrode was inserted through the wall of the LCX so that the tip of the electrode $(2-3 \mathrm{~mm})$ was in contact with the intimal lining of the vessel. The electrode was connected in series to a 250,000 -ohm potentiometer, a 9-volt nickel-cadmium battery, and a digital ammeter (53). The circuit was completed by suturing a disc electrode to a subcutaneous region on the chest wall. The stimulating circuit was designed to permit constant monitoring and easy adjustment of the direct anodal current delivered to the intimal surface of the LCX. After basal hemodynamic measurements were recorded, constant infusion of BMY21190 (1 mg/kg over $30 \mathrm{~min})$ or an equivalent volume of vehicle was delivered via the left jugular cannula. A constant infusion rate of $0.5 \mathrm{ml} / \mathrm{min}$ was maintained by an infusion pump. Thirty minutes after the start of the infusion, electrical stimulation of the LCX was initiated at $100 \mu \mathrm{A}$ via the implanted silver wire electrode. Low amperage electrical stimulation of the canine LCX consistently produced occlusive coronary artery thrombosis (Fig. 2) $(42,53)$.

Our model, in which intimal injury produced by low-amperage electrical stimulation of 


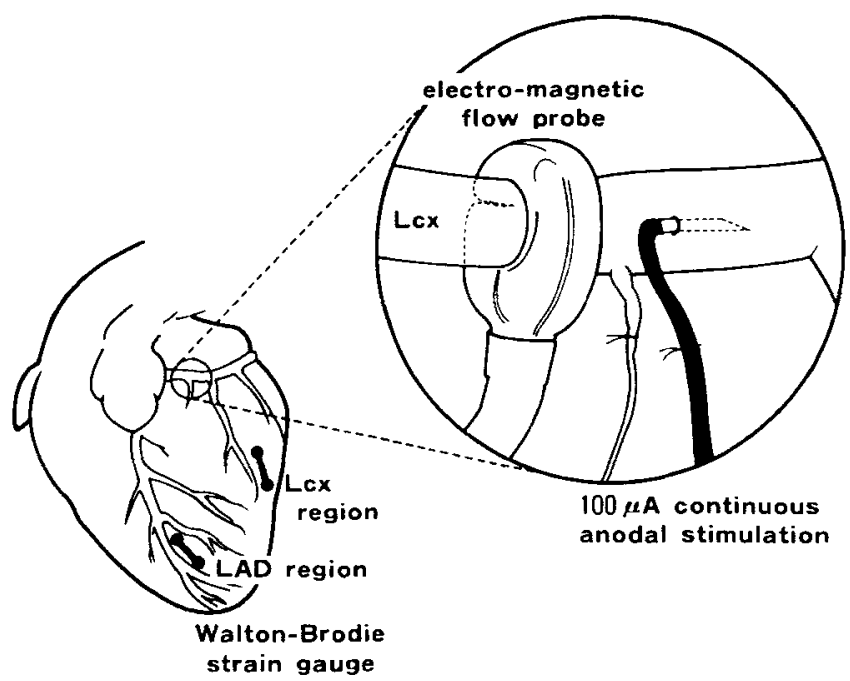

FIG. 2. Surgical procedure and anodal current stimulation in the canine heart. Adapted from ref. 42.

the LCX induces platelet adhesion and secondary recruitment of platelets to form aggregates, is a realistic simulation of coronary artery thrombus formation. The intimal platelet thrombus in our model is stabilized by the incorporation of fibrin into the growing thrombotic mass, and this developed thrombus shows morphological $(42,53)$ and compositional characteristics similar to those of human coronary artery thrombi $(10,44,53$, 55). Thus, this method of inducing coronary artery thrombosis provides an appropriate model for studying the antithrombotic properties of compounds such as BMY21190.

BMY21190 or its vehicle was administered twice: before stimulation and $3 \mathrm{hr}$ after stimulation (Fig. 3). Stimulation of the LCX was continued for $6 \mathrm{hr}$ until LCX decreased to zero for at least $2 \mathrm{~min}$ (Fig. 3). The dogs were sacrificed by spontaneous or electricallyinduced fibrillation. The thrombus present at the site of the electrical injury was removed from the intimal surface of the LCX and the thrombus wet weight was measured on an analytical balance. Values shown in this review are presented as mean \pm SD.

Occlusive LCX thrombosis is determined primarily on the basis of total cessation (Fig. 3 ) of LCX blood flow (42). The time when thrombotic occlusion of the vessel occurs is readily determined by continuously monitoring the LCX blood flow. Complete cessation of the LCX blood flow occurred after approximately $3.2 \mathrm{hr}$ of stimulation. However, signs of developed ischemia were evident as early as $45 \mathrm{~min}$ of the stimulation period. At this time, a reduction of the left ventricular isometric force in the LCX-perfused region of the myocardium, an alternation in the phasic coronary blood flow wave form, and a reduction in mean coronary blood flow were evidence that LCX thrombosis was occurring. After this, ST-segment elevation was recorded by the epicardial electrode situated in the LCX-dependent region of the myocardium. The left ventricular force in this region was further diminished. Occlusion and reperfusion of the coronary artery were repeated throughout the experiment. The earliest complete LCX occlusion by intravascular thrombosis occurred 75 min after the initiation of LCX coronary artery stimulation and terminated in ventricular fibrillation. Further elevation of the epicardial electrogram ST segments occurred as the LCX flow was reduced to zero. Isometric left ventricular contractile 

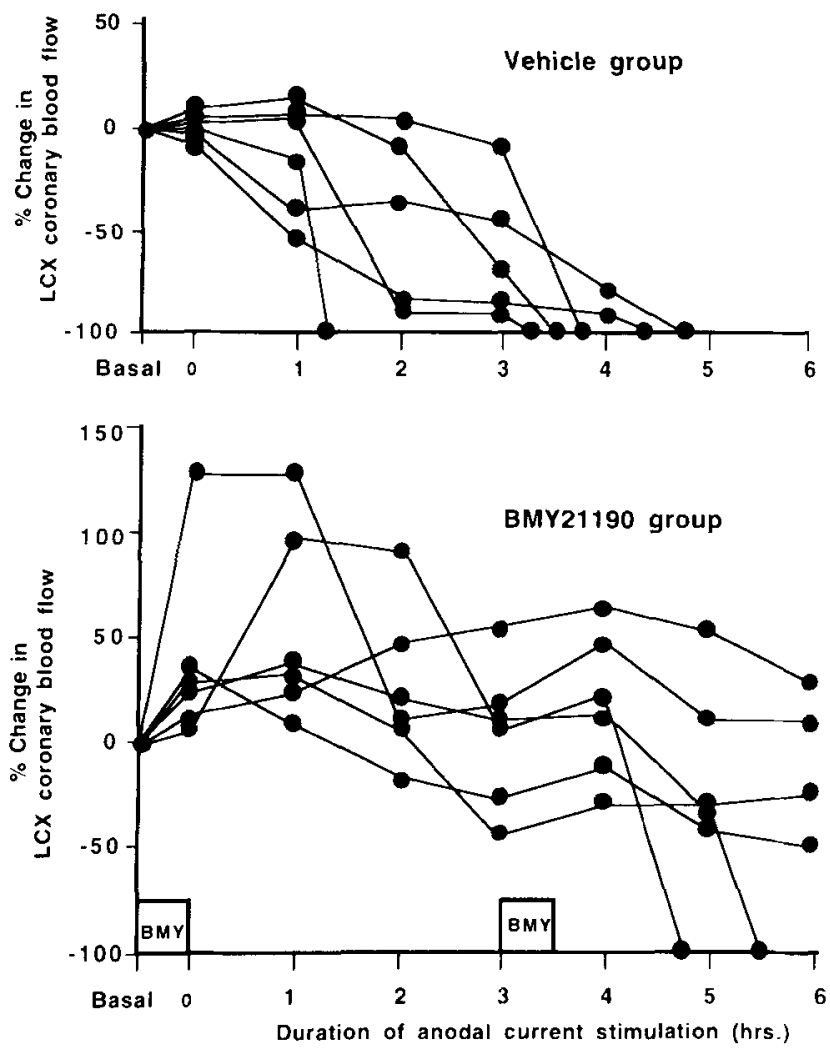

FIG. 3. Changes in left circumflex coronary artery blood flow for each dog in the vehicle and BMY21190 (1 $\mathrm{mg} / \mathrm{kg}$ i.v.) treatment groups. Complete cessation of LCX blood flow as a result of thrombotic occlusion of the vessel is indicated by lines that intercept the abscissa. Lines that terminate before the 6-hr time point indicate spontaneous ventricular fibrillation. Adapted from ref. 42 .

force was markedly reduced in both the ischemic (LCX) and the nonischemic regions. Finally, as indicated in Fig. 3, the LCX coronary blood flow of the control animals progressively declined over the course of the experiment until it completely ceased. Treatment of the animals with BMY21190 at a dose of $1 \mathrm{mg} / \mathrm{kg}$ i.v. prevented this decline. Thus, BMY21190 prolonged the life span of dogs in this coronary ischemic model. Furthermore, a second infusion of BMY21190 was able to dilate the coronary artery during the anodal current injury (42) (Fig. 3). Time to first hyperemia was observed significantly earlier in the vehicle as compared with the BMY21190-treated group during the LCX stimulation (Table 1). The average thrombotic mass that developed in response to intimal injury of the LCX coronary artery was significantly smaller in animals treated with BMY21190 than in the control vehicle dogs (Table 1). There was a $67 \%$ reduction in the incidence of occlusive LCX coronary thrombosis in the BMY21190-treated group ( 2 of 6 dogs occluded) as compared with the control vehicle group ( 6 of 6 dogs occluded) during the 6-hr stimulation period. The difference is significant (Fisher's Exact; $\mathrm{p}=$ 0.03 ).

Under the same experimental conditions, BMY20844 induced similar effects to those 
TABLE 1. Antithrombotic effect of BMY21190 on reactive hyperemic response and thrombus size in a canine model of coronary artery thrombosis

\begin{tabular}{lcc}
\hline & $\begin{array}{c}\text { Vehicle } \\
(\mathrm{n}=6)\end{array}$ & $\begin{array}{c}\text { BMY21190 } \\
(1 \mathrm{mg} / \mathrm{kg} \text { i.v. })(\mathrm{n}=6)\end{array}$ \\
\hline $\begin{array}{l}\text { Time to first hyperemia (min) } \\
\text { Time to occlusion (min) }\end{array}$ & $142.0 \pm 58.3$ & $327.5 \pm 50.6^{* * *}$ \\
$\begin{array}{l}\text { Ratio of experiments where at least one } \\
\text { response occurred }\end{array}$ & $217.5 \pm 55.9$ & $340.0 \pm 40.0^{*}$ \\
$\begin{array}{l}\text { Average number of hyperemia episodes } \\
\text { per experiment (n) }\end{array}$ & $6 / 6$ & $2 / 6^{*}$ \\
$\begin{array}{l}\text { Average hyperemia magnitude (ml/min) } \\
\text { Thrombus size (mg) }\end{array}$ & $2.8 \pm 6.3$ & $0.7 \pm 0.2$ \\
\hline
\end{tabular}

Mean $\pm \mathrm{SD}$.

${ }^{*} p<0.05 ;{ }^{* * *} p<0.001$ vs. vehicle.

Occlusive thrombi formation followed by spontaneous ventricular fibrillation occurred in all 6 of the 6 dogs in the vehicle group and in 2 of 6 dogs that received BMY21190. The other dogs in the BMY21190 group were sacrificed by electrical ventricular fibrillation at $360 \mathrm{~min}$. The average time to complete thrombi occlusion of the LCX is included in the data of sacrificed dogs. Adapted from ref. 42.

of BMY21190 on time to first hyperemia and thrombus size in a dose-dependent manner (43) (Table 2). There was a 65\% reduction in the incidence of occlusive LCX coronary thrombosis in the BMY20844-treated group ( 3 of 11 dogs occluded) as compared with the control vehicle group ( 7 of 9 dogs occluded).

\section{Ex vivo Aggregation Study}

Ex vivo aggregometry refers to experiments in which aggregometry was performed in vitro on platelet rich plasma (PRP) samples obtained from dogs dosed with BMY21190 $(1 \mathrm{mg} / \mathrm{kg})$. Platelet reactivity was assessed in vitro using PRP obtained from venous blood collected in $3.8 \%$ citrate $(1 \mathrm{ml} / 10 \mathrm{ml}$ ) before stimulation (prestimulation) and $4 \mathrm{hr}$ after stimulation (poststimulation). The blood was centrifuged at $380 \times g$ for 5 min to obtain the PRP and again at $2200 \times g$ for 10 min to yield platelet poor plasma (PPP). The PRP was adjusted to 200,000 platelets/ $\mu l$ by adding PPP. Aggregation responses were measured within 15 min of PRP preparation using a PAP-3 platelet aggregometer (Bio Data Corp., Willow Grove, PA) to record the percentage of change in the light transmission of

TABLE 2. Antithrombotic effect of BMY20844 on reactive hyperemic response and thrombus size in a canine model of coronary artery thrombosis

\begin{tabular}{lccc} 
& & \multicolumn{2}{c}{ BMY20844 } \\
\cline { 3 - 4 } & Vehicle & $1 \mathrm{mg} / \mathrm{kg} \mathrm{i.v.}$ & $3 \mathrm{mg} / \mathrm{kg} \mathrm{i.v.}$ \\
\hline $\begin{array}{l}\text { Time to first hyperemia } \\
\text { (min) }\end{array}$ & $\begin{array}{c}106.1 \pm 63.4 \\
(\mathrm{n}=9)\end{array}$ & $\begin{array}{c}256.0 \pm 127.2^{*} \\
(\mathrm{n}=5)\end{array}$ & $\begin{array}{c}302.0 \pm 60.8^{* * * *} \\
(\mathrm{n}=6)\end{array}$ \\
$\begin{array}{c}\text { Thrombus size } \\
\text { (mg) }\end{array}$ & $\begin{array}{c}22.5 \pm 9.0 \\
(\mathrm{n}=9)\end{array}$ & $\begin{array}{c}10.3 \pm 3.2^{*} \\
(\mathrm{n}=5)\end{array}$ & $\begin{array}{c}5.4 \pm 0.9^{*} \\
(\mathrm{n}=6)\end{array}$ \\
\hline
\end{tabular}

Mean \pm SD

$* p<0.05 ; * * * p<.001$ vs. vehicle.

Adapted from ref. 44. 
PRP (set at $0 \%$ ) relative to PPP (set at $100 \%$ ). Aggregation was initiated by adding $50 \mu \mathrm{l}$ of either ADP $(23.4,58.5$, or $117 \mu \mathrm{M})$ (Sigma Chemical Co., St. Louis, MO), collagen $(1 / 100,1 / 800$, or $1 / 1600)$ (Ethicon Collagen Dispersion), or arachidonic acid $(0.325$ or $0.65 \mathrm{mM}$ ) (Sigma Chemical Co., St. Louis, MO) to $450 \mu \mathrm{l}$ of PRP. A total of eight different concentrations of three compounds was tested. Posttreatment responses for each animal were compared with the prestimulation responses. The data are shown in Table 3. Ex vivo platelet aggregation in response to $\mathrm{ADP}$, arachidonic acid, and collagen was significantly inhibited by BMY21190. There were no significant changes in the platelet counts after administration of BMY21190.

Infused at a dose of $1 \mathrm{mg} / \mathrm{kg}$ BMY21190 inhibited ex vivo platelet aggregation and prevented thrombotic occlusion of the LCX at the site of the electrically induced intimal injury. Postmortem examination of the LCX coronary artery revealed that in dogs whose LCX coronary blood flow had stopped, intravascular thrombi completely filled the arterial lumen. This progressive decline and ultimate cessation of LCX blood flow correlate with the complete thrombotic filling of the vascular lumen. The vasodilating properties of BMY21190 may play a role in maintaining the LCX blood flow by relaxing vascular tone and permitting blood to flow between the arterial wall and the thrombotic mass.

Under the same conditions, ex vivo platelet aggregation in response to arachdonic acid was inhibited significantly by BMY20844 (44). No significant changes were demonstrated in the platelet counts after administration of BMY20844 (1 mg/kg i.v.). In rats significant inhibition of collagen- and/or ADP-induced aggregation by BMY20844 was observed ex vivo two hr after oral administration in a water suspension (8).

\section{HEMODYNAMIC EFFECTS OF BMY21190}

\section{Effects of BMY21190 in a Canine Model of Coronary Artery Thrombosis}

Hemodynamic data were recorded continuously during the course of the experiment on a six-channel Grass polygraph. Arterial blood pressure transducer was attached to a polyethylene catheter that was placed in the ascending aorta via the left carotid artery. Segmental left ventricular isometric contractile force in the regions of the myocardium which depend on the LCX and the left anterior descending coronary artery (LAD) was measured with a Brodie-Walton strain gauge arch.

A summary of the hemodynamic effects of BMY21190 after $30 \mathrm{~min}$ of infusion is

TABLE 3. Effects of BMY21190 (1.0 mg/kg i.v.) on ex vivo aggregation in a canine model of coronary artery thrombosis

\begin{tabular}{lccrr}
\hline & \multicolumn{2}{c}{ Vehicle $(\mathrm{n}=8)$} & \multicolumn{2}{c}{ BMY21 $190(\mathrm{n}=6)$} \\
& pre & post & & \multicolumn{1}{c}{ post } \\
\hline Platelet aggregation $(\%)$ & & & & \\
ADP $(58.5 \mu \mathrm{M})$ & $50.6 \pm 20.1$ & $49.3 \pm 17.5$ & $54.3 \pm 27.7$ & $22.5 \pm 12.5^{*}$ \\
AA $(0.65 \mathrm{mM})$ & $51.0 \pm 30.5$ & $54.0 \pm 30.5$ & $66.0 \pm 37.7$ & $8.8 \pm 7.6^{*}$ \\
Collagen $(1: 100)$ & $61.1 \pm 8.2$ & $63.0 \pm 18.7$ & $72.0 \pm 17.4$ & $23.8 \pm 23.7^{*}$ \\
\hline
\end{tabular}

Mean \pm SD.

${ }^{*} p<0.05$ per v. post.

AA: arachidonic acid.

Adapted from ref. 42 . 
shown in Table 4. BMY21190 exhibits a pronounced antithrombotic effect when administered at a dose of $1 \mathrm{mg} / \mathrm{kg}$ i.v. Table 4 also indicates the marked hemodynamic effects of BMY21190. Although no significant changes were observed in the double product or tension, a reflex elevation of heart rate was demonstrated in the BMY21190-treated animals. The largest reduction in MAP occurred in the BMY21190 $(1 \mathrm{mg} / \mathrm{kg})$ group where, after 30 min of infusion, the MAP was reduced by $67 \%$ compared with the basal reading. After the first hyperemia, the LCX blood flow steadily declined to complete cessation in both control and BMY21 190 groups. All control animals developed occlusive thrombi. BMY21190, infused at a dose of $1 \mathrm{mg} / \mathrm{kg}$, prevented the decline and eventual cessation of LCX blood flow characteristic in the control group. The left ventricular isometric force of the control dogs also declined slightly over the course of the experiment. The BMY21190-induced alterations in the decline of the left ventricular force were relatively small. A second infusion of BMY21190 after thrombotic occlusion of the LCX increased coronary blood flow. There also were marked differences between the BMY21190-treated and control animals with respect to intravascular thrombotic mass. These findings suggest that BMY21190 prevents occlusion of the LCX primarily by inhibiting thrombus formation at the site of intimal injury.

The hemodynamic effects of BMY21190 are similar to those of other cAMP-PDE inhibitors. BMY21190 is a vasodilator which produces a reduction in arterial blood pressure and an increase in heart rate. BMY21190 and other closely related compounds

TABLE 4. Hemodynamic effects of BMY21190 in a canine model of coronary artery thrombosis

\begin{tabular}{|c|c|c|}
\hline & $\begin{array}{l}\text { Vehicle } \\
(n=9)\end{array}$ & $\begin{array}{c}\text { BMY21190 } \\
(1 \mathrm{mg} / \mathrm{kg} \text { i.v. })(\mathrm{n}=6)\end{array}$ \\
\hline \multicolumn{3}{|c|}{ Heart Rate (bpm) } \\
\hline before & $156.2 \pm 6.5$ & $157.6 \pm 5.3$ \\
\hline after & $161.1 \pm 8.0$ & $215.3 \pm 11.6$ \\
\hline $\mathbf{P}$ & ns & $\mathrm{P}<0.001$ \\
\hline \multicolumn{3}{|c|}{ Mean AP $(\mathrm{mm} \mathrm{Hg})$} \\
\hline before & $104.8 \pm 12.9$ & $108.6 \pm 7.3$ \\
\hline after & $106.2 \pm 4.1$ & $72.5 \pm 4.5$ \\
\hline $\mathrm{P}$ & ns & $P<0.001$ \\
\hline \multicolumn{3}{|c|}{ Mean CBF $(\mathrm{ml} / \mathrm{min})$} \\
\hline before & $26.4 \pm 2.2$ & $31.8 \pm 7.2$ \\
\hline after & $26.2 \pm 2.1$ & $40.5 \pm 8.9$ \\
\hline $\mathrm{P}$ & ns & $P<0.02$ \\
\hline \multicolumn{3}{|c|}{ Tension-LAD (g) } \\
\hline before & $74.5 \pm 11.3$ & $71.6 \pm 9.7$ \\
\hline after & $80 . \pm 12.8$ & $78.3 \pm 12.9$ \\
\hline P & ns & ns \\
\hline \multicolumn{3}{|c|}{ Tension-LCX (g) } \\
\hline before & $74.7 \pm 6.1$ & $62.2 \pm$ \\
\hline after & $78.3 \pm 6.5$ & $64.6 \pm$ \\
\hline $\mathrm{P}$ & ns & $\mathrm{ns}$ \\
\hline
\end{tabular}

Mean $\pm S D$.

After $=30 \mathrm{~min}$ after drug administration.

AP: arterial pressure; CBF: coronary blood flow; LAD: left anterior descending coronary artery; LCX: left circumflex coronary artery.

Adapted from ref. 42. 
have been shown to significantly inhibit platelet cAMP-PDE at low nanomolar doses (40). With systemic infusion at a dose of $1 \mathrm{mg} / \mathrm{kg}$ BMY21190 resulted in a marked inhibition of platelet activation measured ex vivo, with no significant change in ventricular contractile force. These pharmacological actions appeared to be the effect of a direct action on cardiac and vascular smooth muscle and were generally seen at doses higher than those required to produce significant effects on platelet aggregation $(12,14,20)$. Amrinone and milrinone inhibit platelet activation in vitro with an efficiency that parallels their abilities to inhibit platelet cAMP-PDE and to increase myocardial contractile force $(5,62,64)$. On the other hand, administration of BMY21190 did not cause any significant positive inotropic effect in the present canine model of coronary artery thrombosis.

\section{Effects of Intracoronary Administration of BMY21190 on the Coronary Blood Flow and Oxygen Content}

In order to elucidate the direct effect of BMY21190 on regional tension development and coronary blood flow and oxygen content, BMY21 190 was administered directly into the coronary circulation in the canine heart (42). Male mongrel dogs were anesthetized with dial urethane $(0.6 \mathrm{mg} / \mathrm{kg}$ i.v. $)$ and ventilated under positive pressure with room air using a Harvard respirator pump. Tidal volume and respiratory rate were adjusted to maintain blood $\mathrm{pH}, \mathrm{PO}_{2}$, and $\mathrm{PCO}_{2}$ within normal limits (Instrument Lab., Blood Gas Analyzer, Micro 13). Distal to the first diagonal branch, $1 \mathrm{~cm}$ of the LAD was isolated from surrounding tissue by careful blunt dissection. Within this isolated region, an electromagnetic flow probe was affixed. An intracoronary catheter for the drug infusion was inserted through the vessel wall of the LAD at a distance $3 \mathrm{~mm}$ distal to the electromagnetic flow probe. Patency of the intracoronary catheter was maintained throughout the experiment by infusing a $0.9 \%$ saline solution at a rate of $0.3 \mathrm{ml} / \mathrm{min}$. A segment of the great coronary vein was also isolated near the LAD area. An intracoronary venous catheter was placed in the great vein draining the LAD region to sample coronary venous blood. Another tube was inserted into the left atrial appendage (LA) for the withdrawal of arterial blood. Atrial pacing was performed by a Grass model S-44 stimulator and a Grass model PSIU-6 isolation unit. Propranolol $(0.5 \mathrm{ml} / \mathrm{kg}$ i.v. $)$ was administered slowly to maintain a constant heart rate. BMY21190 or vehicle was rapidly injected into the coronary artery in $0.2 \mathrm{ml}$. Blood was periodically drawn from the LAD and LA. Atrial and venous oxygen contents were determined before each dose of BMY21190.

As shown in Table 5, BMY21190 (0.01 and $0.03 \mathrm{mg} / \mathrm{kg}$ i.c.) increased the coronary blood flow significantly. The oxygen content of the left atrial appendage (A) did not change after BMY21190 (0.01 mg/kg i.c.) administration, but the oxygen content of the great coronary vein (V) in the BMY21190-distributed area increased significantly. BMY21190 (0.01 mg/kg i.c.) reduced the oxygen A-V difference significantly (Table 6). BMY21190 also caused significant coronary vasodilation without increasing myocardial oxygen consumption.

As shown in Fig. 4 isometric tension in the area of the LAD was significantly increased after BMY21190 (0.01 mg/kg i.c.) administration. A large dose of BMY21190 (0.1 $\mathrm{mg} / \mathrm{kg}$ i.c.), however, produced a significant negative inotropic effect. This negative inotropic effect was significantly reversed by verapamil $(0.5 \mathrm{mg} / \mathrm{kg}$ i.v. $)$. Diltiazem $(0.5$ $\mathrm{mg} / \mathrm{kg} \mathrm{i} . \mathrm{v}$.), however, did not affect this negative inotropism. In voltage clamp studies, milrinone $(64)$, and amrinone $(37,64)$ increased the amplitude of $\mathrm{I}_{\mathrm{ca}}$. These agents pro- 
TABLE 5. Mean coronary blood flow change after intracoronary injection of BMY21190 in a propranolol-treated canine constant heart rate model with atrial pacing

\begin{tabular}{|c|c|c|}
\hline & \multicolumn{2}{|c|}{$\begin{array}{l}\text { Changes of mean coronary blood flow } \\
\text { (LAD; ml/min) }\end{array}$} \\
\hline & Before & After BMY21190 \\
\hline \multicolumn{3}{|l|}{ BMY21190 (mg/kg) } \\
\hline $0.01(\mathrm{n}=10)$ & $29.9 \pm 9.5$ & $52.8 \pm 19.9^{*}$ \\
\hline $0.03(n=9)$ & $38.1 \pm 16.2$ & $62.9 \pm 24.8^{* * *}$ \\
\hline $0.1(\mathrm{n}=10)$ & $4.14 \pm 16.7$ & $55.8 \pm 28.5$ \\
\hline \multicolumn{3}{|c|}{$\begin{array}{l}\text { Mean } \pm \mathrm{SD} \text {. } \\
{ }^{*} p<0.05 ;{ }^{* *} p<0.001 \text { vs. before. } \\
\text { BMY21190 was given by rapid intracoronary injection in a volume of } 0.2 \mathrm{ml} \text { containing the above amounts } \\
\text { drug. } \\
\text { Adapted from ref. } 42 \text {. }\end{array}$} \\
\hline
\end{tabular}

duced a positive inotropic effect and increased ${ }^{45} \mathrm{Ca}$ uptake that is sensitive to verapamil (50). These results suggest that a large dose of BMY21190 induces an excessive calcium accumulation in the myocardial cells.

\section{Effect of BMY21190 on Coronary Artery Occlusion and Reperfusion}

Ischemic myocardial injury was produced in dogs by means of techniques detailed in previous publications (55). Male mongrel dogs were anesthetized with dial urethane, intubated, and ventilated with room air using a Harvard respirator. The LCX was isolated just before the first diagonal branch. LCX coronary blood flow was measured by placing an electromagnetic flow probe (Carolina Medical Electronics, Inc.) distal to an occlusive ligature. To limit reperfusion arrhythmias and myocardial hemorrhage, the occlusive ligature was adjusted so that basal coronary blood flow was not altered. After measurement of basal coronary blood flow, stenosis of the artery was produced by affixing a silk ligature around both the vessel and an 18- or 19-gauge needle. The degree of partial constriction was adjusted to reduce by at least $70 \%$ the hyperemic response to a $10-\mathrm{sec}$ occlusion without altering basal flow. Five minutes later, myocardial ischemia was produced by clamping the LCX flow completely for a period of $90 \mathrm{~min}$. The mechanical

TABLE 6. Effect of intracoronary (LAD) administration of BMY21190 on the oxygen content of canine left atrial appendage and great coronary venous blood

\begin{tabular}{lcc}
\hline & $\begin{array}{c}\text { Pre-drug } \\
(\mathrm{n}=6)\end{array}$ & $\begin{array}{c}\text { Post BMY21190 } \\
(0.01 \mathrm{mg} / \mathrm{kg} \mathrm{i.c.})(\mathrm{n}=6)\end{array}$ \\
\hline Oxygen content (\%) & & \\
LA(A) & $16.3 \pm 3.1$ & $15.4 \pm 5.4$ \\
Great vein (V) & $4.2 \pm 1.1$ & $7.8 \pm 3.6^{*}$ \\
A-V & $12.5 \pm 2.2$ & $7.7 \pm 2.6^{*}$ \\
\hline
\end{tabular}

Mean \pm SD.

$* p<0.05$ vs. pre-drug.

LA: left atrium; A-V: A-V difference.

Adapted from ref. 42 . 


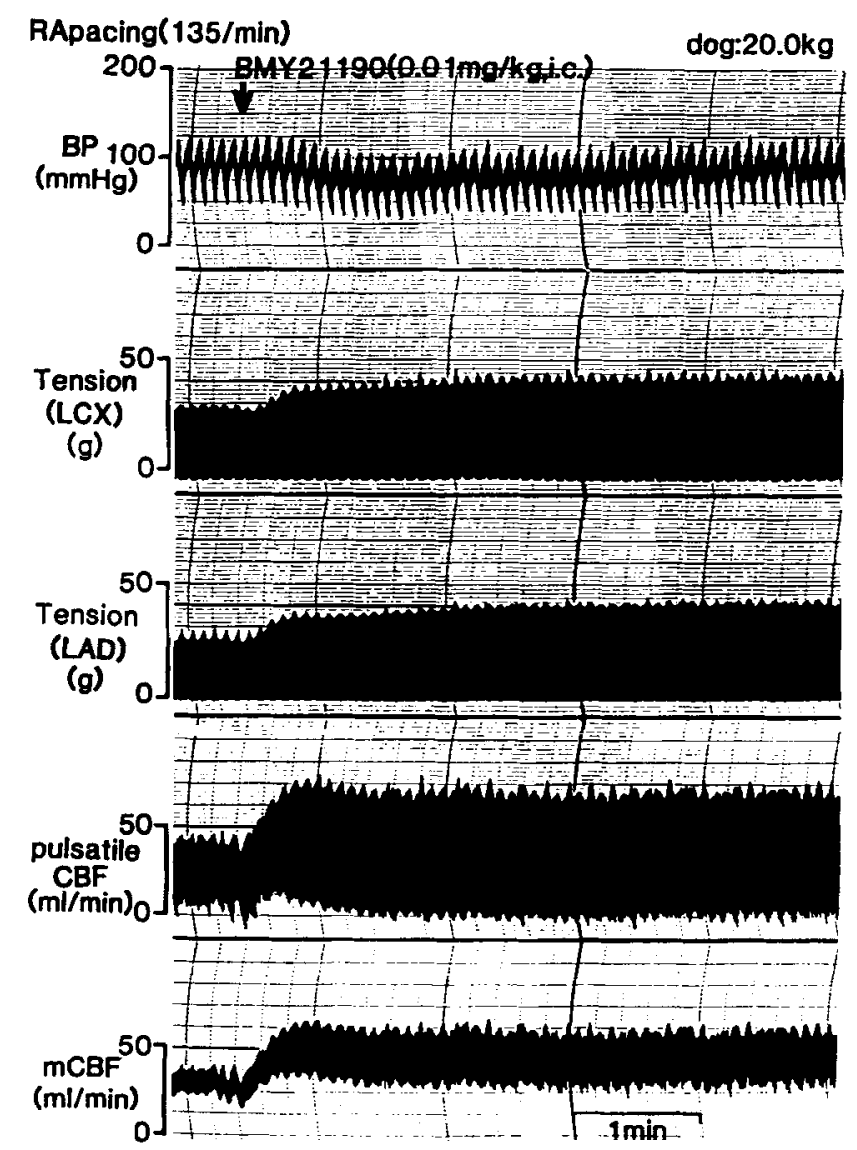

FIG. 4. The effect of BMY $21190(0.01 \mathrm{mg} / \mathrm{kg}$ i.c. $)$ on various cardiovascular parameters in the canine constant heart rate model. Adapted from ref. 42.

occlusion was released gradually over a period of $30 \mathrm{~min}$ to prevent reperfusion induced ventricular fibrillation. Dogs remained anesthetized until sacrificed by electrical fibrillation after the 6-hr reperfusion period. The experimental protocol consisted of a 90 -min occlusion and 6-hr reperfusion of the LCX.

While there is little doubt that platelets accumulate within infarcted myocardium $(45,56)$, the role of platelets in the development of myocardial infarction is unclear. Platelets have been shown to form microemboli in ischemic myocardium (45) and to release vasoactive substances, including TXA $_{2}(25,63)$. Reperfusion produces a 10 -fold increase in platelet accumulation, as compared to that found with permanent occlusion $(33,53)$. BMY21190 induced a significantly higher heart rate and lower mean arterial blood pressure than observed in the vehicle group. In general, the increase in pressure-rate products is an unfavorable action of cAMP-PDE inhibitors in patients with ischemic heart disease. Although BMY21190 induced a rise in heart rate, it had no significant effect on the pressure-rate products. Mean LCX coronary blood flow after reperfusion was significantly less than the preocclusion flow in the vehicle group. BMY21190 administration, however, maintained coronary blood flow after reperfusion. There was a significant 
difference between the vehicle and the BMY21190 groups with respect to mean coronary blood flow after reperfusion.

\section{REDUCTION OF ISCHEMIC MYOCARDIAL INJURY}

\section{Postmortem Quantification of Infarct Size}

After a 90-min occlusion and 6-hr reperfusion of the LCX, myocardial infarct size was quantified by an in vitro dual perfusion technique previously described (55). Cannulae were inserted into the LCX immediately distal to the site of LCX occlusion and into the aorta above the coronary ostia. The LCX coronary bed was perfused with $1.5 \%$ triphenyl tetrazolium hydrochloride (TTC) in $20 \mathrm{mM}$ potassium phosphate buffer (pH 7.4, 37 ${ }^{\circ} \mathrm{C}$ ). The aorta was perfused in a retrograde manner with $0.25 \%$ Evans blue dye. Both the LCX region and the remainder of the heart were simultaneously infused with their respective stains at a constant positive pressure of $100 \mathrm{mmHg}$ for $5 \mathrm{~min}$ in a water bath $\left(37^{\circ} \mathrm{C}\right)$. The stained heart was then sliced into six or seven sections, approximately $1.0-\mathrm{cm}$ thick, from apex to base. The area free of the blue dye indicated the area of the left ventricle at risk of infarction. The region of infarcted myocardium within the area at risk was demonstrated by the lack of staining of the tissue when perfused with TTC due to a loss of dehydrogenase enzymes which convert the colorless TTC to a red formazan precipitate.

\section{Analysis of Infarct Size}

More specifically, the upper surface of the transverse ventricular sections were traced carefully onto clear plastic sheets. In order to provide a permanent record of infarct morphology, the areas of each zone were measured by planimetry using a graphic tablet and Apple IIe computer (Apple Computer, Inc., Cupertino, CA, USA). A custom-made software program was used to calculate the masses of the infarct zone and the area at risk from the planimetered areas and the weights of each transverse ventricular section. Infarct size was calculated as a percentage of both the area at risk and the total left ventricle. Previous studies demonstrated that there is an excellent correlation between infarct size derived by the planimetric method and the direct gravimetric measurement (70). The measurement of infarct size using the TTC technique also correlated with the infarct size measured by histological examination. Transmural tissue blocks from the area at risk were obtained from three transverse sections of the hearts.

There is increasing evidence that activated neutrophils cause myocardial injury during the reperfusion of ischemic myocardium $(35,72)$. Reperfusion of ischemic myocardium may have both beneficial and detrimental effects on ischemic cells (7). Myocardial infarction expands with the duration of coronary occlusion (29). Moreover, infarct size may be increased by reperfusion. After occlusion and reperfusion, the infiltration of neutrophils into ischemic myocardium could exacerbate and promote myocardial damage (71). The invading neutrophils may injure the myocardial vasculature by generating oxygen free radicals $(47,54)$. While BMY20844 and BMY21190 increase the concentration of cAMP in leucocytes $(38,43)$, free radical production is inhibited by the agents that produce cAMP accumulation (34). The increase in leukocyte CAMP will inhibit the activation of oxidative burst and chemotaxis.

In order to elucidate the effect on infarct size, BMY21190 was administered before 
reperfusion of the ischemic dog heart. Two dogs failed to complete the protocol due to intractable ventricular fibrillation after reperfusion. Thus, infarct size data are reported for six dogs treated with BMY21190 and for six dogs treated with vehicle (Table 7). As demonstrated previously (71), the gravimetric and planimetric methods of quantifying infarct size were in excellent agreement. For infarct size expressed as a percentage of the area at risk, the equation of liner regression was: planimetric $=1.05$ (gravimetric) + $0.08(\mathrm{r}=0.99, \mathrm{SE}=2.43, \mathrm{n}=14)$. The data of infarct zone weight, risk zone weight, the ratio of infarct zone/left ventricular mass (LV), and area at risk are summarized in Table 7. Total LV mass and risk weight of BMY21190-treated dogs tended to decrease compared with those of vehicle-treated dogs. No significant difference, however, was demonstrated between them. Also, there was no significant difference between the area at risk/LV in BMY21190-treated dogs and that in vehicle-treated dogs. As shown in Table 7 , in the control dogs (vehicle), mean infarct size was $62.4 \pm 9.6 \%$ of the anatomic area at risk. In dogs receiving BMY21190, infarct size averaged $36.1 \pm 17.6 \%$ of the area at risk. Infarct size was significantly different from controls, whether expressed as grams of infarcted tissue or percentages of the area at risk (Table 7).

\section{Relationship Between Infarct Size and Myeloperoxidase Activity}

Because neutrophil infiltration is heterogenous (48), the transmural distribution of myeloperoxidase (MPO) activity across the ischemic region was studied in segments of tissue obtained from the infarct and risk zones. In addition, we examined the correlation between infarct size and MPO activity in a canine model undergoing a 90-min occlusion and 6-hr reperfusion. Bradley et al. (6) have utilized a spectrophotometric assay for the neutrophil-specific MPO enzyme to measure neutrophil accumulation in the ischemic myocardium. MPO serves as a quantitative indicator of neutrophil infiltration (48). MPO, contained within the azurophilic granules of the neutrophils, was liberated as follows. Myocardial tissue was frozen in liquid nitrogen and pulverized. Samples of myocardium

TABLE 7. Effect of BMY21190 on canine infarct size after a 90-min occlusion and 6-hr reperfusion of the left circumflex coronary artery

\begin{tabular}{lcc}
\hline & $\begin{array}{c}\text { Vehicle } \\
(\mathrm{n}=6)\end{array}$ & $\begin{array}{c}\text { BMY21190 } \\
(1 \mathrm{mg} / \mathrm{kg} \mathrm{i.v.})(\mathrm{n}=6)\end{array}$ \\
\hline Gravimetric method & & \\
$\quad$ Body weight $(\mathrm{kg})$ & $15.4 \pm 0.9$ & $14.0 \pm 1.3$ \\
Critical stenosis $(\%)$ & $71.3 \pm 7.2$ & $60.6 \pm 6.0^{*}$ \\
LV weight $(\mathrm{g})$ & $93.4 \pm 13.4$ & $79.1 \pm 39.3$ \\
Area risk weight (g) & $42.8 \pm 7.6$ & $34.9 \pm 8.0$ \\
Infarct zone weight $(\mathrm{g})$ & $24.1 \pm 6.7$ & $13.0 \pm 7.2^{*}$ \\
Planimetric method & & $44.4 \pm 6.3$ \\
Area risk/LV $(\%)$ & $42.3 \pm 11.8$ & $16.1 \pm 7.8$ \\
Infarct zone/LV $(\%)$ & $27.4 \pm 11.4$ & $36.1 \pm 17.6^{*}$ \\
Infarct zone/area risk (\%) & $62.4 \pm 9.6$ & \\
\hline Mean \pm SD. & & \\
$\quad$ * $p<0.05$ vs. vehicle. & & \\
The quantification of the masses of the infarct zone, area at risk and left ventricle was done by both \\
gravimetric and planimetric methods.
\end{tabular}


(50-200 mg) were taken from the central infarct region, the noninfarcted tissue within the area at risk, and the overlapping border between the infarct region and the area at risk. Tissue was homogenized at $4^{\circ} \mathrm{C}$ in $0.5 \%$ hexadecyltrimethyl ammonium bromide (HTAB, Sigma Chemical Co.) buffered with $50 \mathrm{mM}$ potassium phosphate ( $\mathrm{pH} 6.0$ ) with a polytron homogenizer (Kinematica Ag, Littau/Lucerne, Switzerland). The tissue suspensions were then sonicated for $10 \mathrm{sec}$ on ice with a probe sonicator (Heat Systems-Ultrasonics, Inc., New York, NY, USA Model W-375). These samples were then centrifuged $(20,000 \mathrm{~g}$ for $15 \mathrm{~min}$ ) and the supernatants were assayed for MPO activity. MPO was assayed spectrophotometrically by adding $0.05 \mathrm{ml}$ supernatant to $1.45 \mathrm{ml} 50 \mathrm{mM}$ potassium phosphate buffer ( $\mathrm{pH} \mathrm{6.0)}$ with $0.167 \mathrm{mg} / \mathrm{ml}$ o-dianisidine hydrochloride (Sigma Chemical Co.) and $0.0005 \%$ hydrogen peroxide (Sigma Chemical Co.). The change in absorbency was measured at $460 \mathrm{~nm}$ with a Cary 210 Spectrophotometer (Cary Instruments, Monrovia, CA, USA). One unit of MPO (MPO/100 mg tissue weight) activity was diluted to the

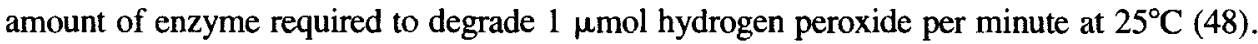

As shown in Fig. 5, the highest MPO activity was found at the risk area where the activity at $6 \mathrm{hr}$ was $0.40 \mathrm{UMPO} / 100 \mathrm{mg}$ tissue. Activity in the central infarct zone was $0.30 \mathrm{U} \mathrm{MPO} / 100 \mathrm{mg}$ tissue. MPO activity $(0.14 \mathrm{U} / 100 \mathrm{mg}$ tissue) obtained from the area at risk treated by BMY (1 mg/kg i.v.), however, was significantly lower than that of the vehicle treated tissue $(\mathrm{p}<0.05)$. The MPO activity in the infarct zone obtained from both groups was almost the same value suggesting that BMY21190 may be effective only on the area at risk. The relationship between MPO activity and infarct size was studied in 12 dogs subjected to a 90 -min occlusion and 6-hr reperfusion. Six of the infarcted dogs

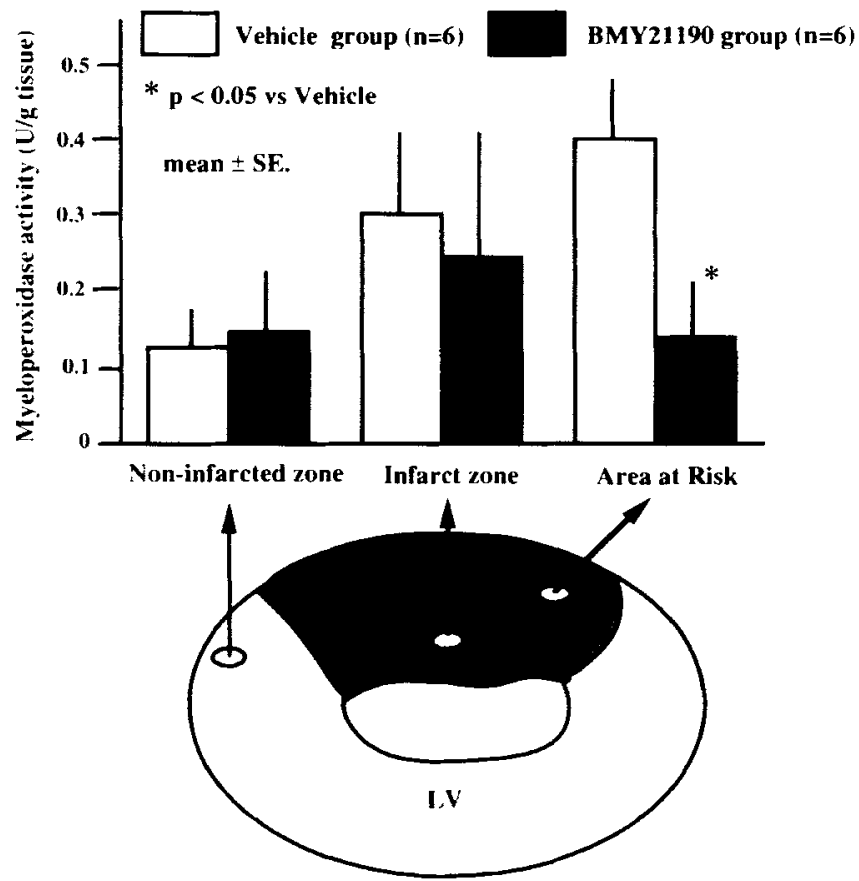

FIG. 5. Effects of BMY21190 on tissue myeloperoxidase activity in a canine model of occlusion and reperfusion. Adapted from ref. 43. 
pretreated with BMY21190 (1 mg/kg i.v.) were also included. The values show the infarct size (ratio area at risk) and the MPO activity obtained from the zone of area at risk. The ratio correlated well with the MPO activity $(\mathrm{r}=0.683, \mathrm{p}<0.02)$. The relation was $\mathrm{y}=$ $2.95 x+11.5$, including both groups $(n=12)$.

Infarcted myocardium from BMY21190-treated dogs showed significantly lower MPO activity than that of vehicle-treated dogs. MPO activity in the area at risk treated with BMY21190 was significantly lower than that in vehicle-treated tissue. However, the MPO activity in the infarct zone obtained from both groups was almost the same. According to the protocol, BMY21190 was injected $45 \mathrm{~min}$ after the occlusion to prevent reperfusion injury. The infarction produced by this protocol may occur in two steps: first, it may occur simply through occlusion ( $13 \mathrm{~g}$ ); secondly, it may develop through reperfusion injury (13 to $24 \mathrm{~g}$ ) induced by neutrophil infiltration. BMY21190 may be effective on the area at risk. In this protocol, BMY21190 does not affect the first step of infarct. For these reasons, the MPO activity in the infarct zone obtained from both groups might have been almost the same.

\section{INOTROPIC AND CHRONOTROPIC EFFECT OF BMY21190 IN ISOLATED RABBIT PAPILLARY MUSCLES AND ATRIAL PREPARATIONS}

BMY21190 was studied for its inotropic and chronotropic actions on rabbit isolated heart muscle preparations. At concentrations between $10^{-7}$ and $10^{-5} M$, BMY 21190 showed a mild but significant positive inotropic effect $(p<0.05)$ of $113.6 \pm 11.8 \%$ $\left(10^{-6} M\right)(\mathrm{n}=9)$ as compared with the vehicle control. Time-to-peak tension was decreased in a concentration-dependent manner (not significant). At a concentration of $10^{-4} M$, BMY21190 reduced the contractile force: $80.7 \pm 9.2 \%$ (p $<0.01$ vs. vehicle group). In an in vivo study in large doses BMY21190 also induced a significant negative inotropic effect (42). This negative inotropic effect was partially reversed by verapamil. BMY21190 did not exert a positive chronotropic effect at concentrations between $10^{-7}$ to $10^{-5} M$ on rabbit isolated atrial preparations. In an in vivo study BMY21190 produced an increase in heart rate. BMY21190 caused a reduction in arterial blood pressure. The change of heart rate induced by BMY21 190, therefore, may be a reflex tachycardia. Thus, BMY20844 and BMY21190 possess antithrombotic and moderate inotropic actions. In isolated cardiac tissues, PDE inhibitors exert a positive inotropic effect which is probably mediated by cAMP $(11,49)$. This suggests that PDE III is the molecular target for some cardiotonic drugs (19).

The effect of inotropic therapy on myocardial infarct size was not completely evaluated. Previous investigators have demonstrated, however, that dobutamine does not increase infarct size in humans (16) or dogs (32). Further studies are needed concerning the effects similar to those of dobutamine.

It is suggested that the new inotropic vasodilator BMY21190 may have beneficial hemodynamic effects in patients with congestive heart failure. In numerous studies milrinone and enoximone have clearly been shown to improve hemodynamics in patients with congestive heart failure (27). The strength of milrinone and other type III PDE inhibitors as positive inotropes and vasorelaxants parallels their potency as cardiac and vascular type III PDE inhibitors (61). These data support the concept that a single mechanism of action may account for the cardiotonic and vasodilator efficacy of milrinone and other type III PDE isozyme inhibitors (11). 


\section{MYOCARDIAL CAMP LEVELS}

The precise mechanism by which BMY21190 induces neutrophil infiltration is unknown. The type III cAMP-PDE isozyme in the heart is the target of several agents (11) that increase contractile force (18) and decrease peripheral vascular resistance, as well as inhibit platelet aggregation. These agents produce an increase in cardiac inotropy and in ${ }^{45} \mathrm{Ca}$ uptake $(37,50,64)$. The activation of oxidative metabolism is reported to be modulated by cyclic nucleotides and cAMP-accumulating agents (34). Free radical production is inhibited by exogenously added cAMP and agents which increase the levels of intracellular cAMP (34).

We determined the level of myocardial cAMP content in the isolated rabbit heart. The hearts of male New Zealand white rabbits $(1.0-1.5 \mathrm{~kg})$ were quickly isolated. Rabbit heart muscles were placed in contact with platinum electrodes and stimulated using a Grass stimulator (S88) set. After incubation, the experiments were performed as follows; the procedure was based on that as described by Sabina et al. (57). Prior to drug (or vehicle) addition and $10 \mathrm{~min}$ after the final concentration of BMY20844 and BMY21190, the heart muscle preparations were removed from the organ bath. The specimens were plunged and pressed between the jaws of "quick-freeze tongs," which had been cooled within $5 \mathrm{sec}$ using liquid nitrogen. The samples were ground to a fine powder with a mortar and pestle in an ice bucket surrounded by dry ice in acetone. The powder was centrifuged at 10,000 $\times 4^{\circ} \mathrm{C}$ for $15 \mathrm{~min}$. To aliquots of $100 \mu \mathrm{l}$ of supernatant, $1 \mathrm{ml}$ of water-saturated ether was added and the mixtures were centrifuged under the same conditions. Ether extraction was repeated three more times. After this procedure, the aliquots of supernatant were boiled for 1 min. Radioimmunoassay of tissue cAMP (26) was carried out after acetylation using triethylamine and acetic anhydride. As shown in Table 8, both BMY20844 $\left(10^{-6} M\right)$ and BMY21190 $\left(10^{-6} M\right)$ significantly increased myocardial cAMP content compared with that of the vehicle-treated rabbit heart. These drugs have a significant positive inotropic effect on isolated rabbit papillary muscle, suggesting a relationship between the positive inotropic action and the tissue level of cAMP. BMY21190 induces both cAMP and calcium accumulation in the myocardial cells and may protect them from exposure to oxygen radicals.

\section{SUMMARY}

Compounds containing the imidazoquinoline nucleus are a new class of potent broadspectrum inhibitors of platelet aggregation (38). BMY21190 is an ether-linked side chain derivative with a simply substituted imidazoquinoline. These compounds are potent inhibitors of platelet cAMP PDE $\left(\mathrm{IC}_{50} 10^{-8} M\right)$ but have little effect on platelet homogenate cGMP PDE $\left(\mathrm{IC}_{50}>10^{-5} M\right)(8)$. BMY21190 was evaluated for its ability to modify the development of experimental thrombosis resulting from anodal current injury (100 $\mu \mathrm{A}$ for $6 \mathrm{hr}$ ) to the intimal surface of the left circumflex coronary artery (LCX) in the anesthetized dog (42). After a 30-min administration of BMY21190, heart rate and mean coronary blood flow were increased significantly and mean arterial pressure was decreased. The myocardial tension of the LAD and LCX areas, however, did not change significantly after BMY21190 infusion. During LCX stimulation, the first LCX occlusion and the hyperemic reaction occurred significantly earlier in the control group than in the BMY21190 group. Compared with the controls, BMY21190 treatment reduced the de- 
TABLE 8. Myocardial cAMP levels of BMY20844- and BMY21190-treated rabbit heart

\begin{tabular}{|c|c|c|c|}
\hline & $\begin{array}{l}\text { Vehicle } \\
(\mathrm{n}=8)\end{array}$ & $\begin{array}{c}\text { BMY20844 } \\
10^{-6} M(\mathrm{n}=7)\end{array}$ & $\begin{array}{c}\text { BMY21190 } \\
10^{-6} M(\mathrm{n}=7)\end{array}$ \\
\hline \multicolumn{4}{|c|}{ cAMP contents ( $\mathrm{p}$ moles $/ \mathrm{mg}$ tissue) } \\
\hline Right ventricle & $0.524 \pm 0.190$ & $0.793 \pm 0.191^{*}$ & $0.952 \pm 0.315^{*}$ \\
\hline Left ventricle & $0.314 \pm 0.166$ & $0.545 \pm 0.423$ & $0.911 \pm 0.276^{* *}$ \\
\hline \multicolumn{4}{|c|}{$\begin{array}{l}\text { Mean } \pm \text { SD. } \\
{ }^{*} p<0.05, * * p<0.01 \text { vs. vehicle. } \\
\mathrm{n}=\text { numbers of rabbits. } \\
\text { Dose }\left(10^{-6} M\right) \text { shows the final concent }\end{array}$} \\
\hline
\end{tabular}

velopment of LCX thrombus mass. In ex vivo studies, platelet aggregation in response to arachidonic acid, ADP, or collagen was inhibited by BMY21190.

The precise mechanism by which BMY21190 induces platelet inhibition is unknown. Agents capable of increasing intraplatelet accumulation of cAMP effectively inhibit platelet aggregation induced by broad-spectrum agonists $(8,41,60)$. Elevation of platelet cAMP leads to phosphorylation of platelet myosin light chain kinase by a cAMPdependent protein kinase (22). The cAMP-mediated phosphorylated and inactivated form of myosin reduces actin-myosin interaction, platelet contraction, and granule secretion (22).

The effect of BMY21190 on infarct size was also evaluated using a canine ischemic model with 90-min occlusion and 6-hr reperfusion of the left coronary artery (42). The infarct zone/area at risk of the BMY21 190 group was significantly smaller than that of the vehicle group. Myeloperoxidase activity, an indicator of neutrophil infiltration, measured in the area at risk from hearts of the BMY21190-treated group was significantly lower than that in the vehicle treated tissue. BMY21190 may reduce the infarct size partly through the inhibition of neutrophil infiltration in the canine model. BMY21190 achieved a desired antithrombotic effect without thrombocytopenic side effects. In addition, the strong coronary vasodilating and mild inotropic actions of BMY21190 had a significant impact on cardiac hemodynamics. BMY21190 and BMY20844 represent the first compounds of this series to be selected for clinical testing (40). BMY20844 was selected from this series as a candidate for clinical assessment and has been studied in some detail at the biochemical (60) and pharmacological levels (8).

\section{REFERENCES}

1. Andes AW, Noveck RJ, Fleming JS. Inhibition of platelet production induced by an antiplatelet drug, analgrelide, in normal volunteers. Thromb Haem 1984;52:325-328.

2. Asano T, Ochiai $Y$, Hidaka $H$. Selective inhibition of separated forms of human platelet cyclic nucleotide phosphodiesterase by platelet aggregation inhibitors. Mol Pharmacol 1977;13:400-406.

3. Baim DS, McDowell AV, Chemiles J, et al. Evaluation of a new bipyridine inotropic agent-milrinone-in patients with severe congestive heart failure. N Engl J Med 1983;309:748-756.

4. Beavo JA. Multiple isozymes of cyclic nucleotide phosphodiesterase. Adv Sec Mess Phosphoprot Res $1988 ; 22: 1-38$.

5. Benedict CR, Mathew B, Rex KA, Cartwright J Jr, Sordahl LA. Correlation of plasma serotonin changes with platelet aggregation in an in vivo dog model of spontaneous occlusive coronary thrombus formation. Circ Res 1986;58:58-67.

6. Bradley PP, Priebat DA. Measurement of cutaneous inflammation: Estimation of neutrophil content with an enzyme marker. J Invest Dermatol 1982;78:206-209. 
7. Braunwald E, Kloner RA. Myocardial reperfusion: A double-wedged sword? J Clin Invest 1985;76:17131719.

8. Buchanan JO, Fleming JS, Cornish BT, et al. Pharmacology of a potent, new antithrombotic agent, 1,3-dihydro-7,8-dimethyl-2H-imidazo[4,5-b] quinolin-2-one (BMY-20844). Thromb Res 1989;56:333346.

9. Degerman E, Belfrange P, Newman AH, Rice KC, Manganielo VC. Purification of the putative hormonesensitive cyclic AMP phosphodiesterase from rat adipose tissue using a derivative of cilostamide as a novel affinity ligand. $J$ Biol Chem 1987;262:5797-5807.

10. DeWood M, Spores J, Notske R, et al. Prevention of total coronary occlusion during the early hours of transmural myocardial infarction. N Engl J Med 1980;303:897-901.

11. Endoh M. Pharmacology of loprinone (E-1020), a new pyridinone inodilator, as a therapeutic agent for acute heart failure. Cardiovasc Drug Rev 1993;11:432-450.

12. Erhardt PW. In search of the digitalis replacement. J Med Chem 1987;30:231-237.

13. Feinstein MB, Egan JJ, Opass EE. Reversal of thrombin-induced myosin phosphorylation and the assembly of cytoskeletal structures in platelets by the adenylate cyclase stimulants prostaglandin $\mathrm{D}_{2}$ and forskolin. $J$ Biol Chem 1983;258:1260-1267.

14. Fleming JS, Buyniski JP, Cavanagh RL, Bierwagen ME. Pharmacology of a potent, new anti-thrombotic agent, 6-methyl-1,2,3,5-tetrahydroimidazo(2,1-6) quinazolin-2-one hydrochloride monohydrate (BL3459). J Pharmacol Exp Ther 1975;194:435-449.

15. Fleming JS, Buchanan JO, Baryla UM, et al. BMY-2163, a new, potent, broad-spectrum inhibitor of blood platelet aggregation and experimental thrombosis. Thromb Haemostasis 1989;62:409.

16. Gillespie TA, Ambos HD, Sobel B, Roberts R. Effects of dobutamine in patients with acute myocardial infarction. Am J Cardiol 1977;39:588-594.

17. Grant PG, Colman RW. Purification and characterization of a human platelet cyclic nucleotide phosphodiesterase. Biochemistry 1984;23:1801-1807.

18. Hagiwara M, Endo T, Kanayama T, Hidaka H. Effect of 1-(3-choloanilino)-4-phenylphthalazine (MY5445), a specific inhibitor of cyclic GMP phosphodiesterase of human platelet aggregation. $J$ Pharmacol Exp Ther 1984;228:467-471.

19. Harrison SA, Reifsnyder DH, Gallis B, Cadd GG, Beavo JA. Isolation and characterization of bovine cardiac muscle cGMP-inhibited phosphodiesterase: A receptor for new cardiotonic drugs. Mol Pharmacol 1986;29:506-514.

20. Hashimoto H, Ishii K, Satoh K, Taira N. Comparison of vasodilator effects of DN-9693, a selective inhibitor of cyclic AMP phosphodiesterase, and isobutyl-methylxanthine, a non-selective one, in dogs. Jpn $J$ Pharmacol 1987:44:405-412.

21. Haslam RJ, Daison MML, Davies T, Lynham JA, McClenoghan MD. Regulation of blood platelet function by cyclic nucleotides. Adv in Cyclic Nucleotide Res 1978;9:533--552.

22. Hathawa DR, Adelstein RS. Human platelet myosin light chain kinase requires the calcium-binding protein calmodulin for activity. Proc Natl Acad Sci USA 1979;76:1653-1657.

23. Hidaka H, Hayashi H, Kohri H, Kimura Y, Hosokawa T, Igawa T, Saitoh Y. Selective inhibitor of platelet cyclic adenosine monophosphate phosphodiesterase, cilostamide, inhibits platelet aggregation. $J$ Pharmacol Exp Ther 1979;211:26-30.

24. Hidaka $H$, Tanaka $T$, Itoh $H$. Selective inhibitors of three forms of cyclic nucleotide phosphodiesterases. Trends Pharmacol. Sci. 1984;5:237-239.

25. Hirsh PD, Campbell WB, Willerson JT, Hills LD. Prostaglandins and ischemic heart disease. Am J Med $1981 ; 71: 1009-1026$.

26. Honma M, Satoh T, Takezawa J, Ui M. An ultrasensitive method for the simultaneous determination of cyclic AMP and cyclic GMP in small-volume samples from blood and tissue. Biochem Med 1977;18:257273.

27. Hood WB. Controlled and uncontrolled studies of phosphodiesterase III inhibitors in contemporary cardiovascular medicine. Am J Cardiol 1989;163:46A-53A

28. Houslay MD, Beavo JA, eds. Isozymes of cyclic nucleotide phosphodiesterases. John Wiley \& Sons, 1990.

29. Jolly SR, Kane WJ, Hook BG, Abrams GD, Kunkel SL, Lucchesi BR. Reduction of myocardial infarct size by neutrophil depletion: Effect of duration of occlusion. Am Heart $J$ 1986;112:682-690.

30. Kauffman RF, Crowe VG, Utterback RDW. A potent selective inhibitor of cyclic nucleotide phosphodiesterase located in the sarcoplasmic reticulum. Mol Pharmacol 1986;30:609-616.

31. Kinney EL, Draganis T, Luderer JR, Demers LM. Mechanism of action of amrinone: Role of thromboxane synthetase inhibition. Prostagland Leuk Med 1983;11:213-214.

32. Kirlin PC, Pitt B, Lucchesi BR. Comparative effects of prenalterol and dobutamine in a canine model of acute ischemic heart failure. J Cardiovasc Pharmacol 1981;3:896-905.

33. Lams KH, Clanton JA, Stames VA, et al. Kinetics and imaging of indium 111-labeled autologous platelet in experimental myocardial infarction. Circulation 1983;67:110-116. 
34. Lehmeyer JE, Johnson RB. Effect of antiinflammatory drugs and agents that elevate intracellular cyclic AMP on the release of toxic oxygen metabolites by phagocytes: studies in a model of tissue-bound IgG. Clin Immunol Immunopathol 1978;9:482-490.

35. Lucchesi BR, Mullane KM. Leukocytes and ischemia-induced myocardial injury. Ann Rev Pharmacol Toxicol 1986;26:201-224.

36. Lugnier C, Schoeffter P, LeBec A, Strouthou E, Stoclet JC. Selective inhibition of cyclic nucleotide phosphodiesterases of human, bovine and rat aorta. Biochem Pharmacol 1986;35:1743-1751.

37. Malecot CO, Arlock P, Katsung BG. Amrinone effects on the electromechanical coupling and depolarization-induced automaticity in ventricular muscle of guinea pigs and ferrets. J Pharmacol Exp Ther 1985; 232:10-19.

38. Meanwell NA, Seiler NA. Inhibitors of platelet cAMP phosphodiesterase. Drugs Future 1990;15:369-390.

39. Meanwell NA. Inhibitors of platelet phosphodiesterase: potential antithrombotic agents. Drug News Prospectives 1991;4:400-413.

40. Meanwell NA, Roth HR, Smith EC, et al. 1,3-Dihydro-2H-imidazo[4,5-b] quinolin-2-ones, Inhibitors of blood platelet cAMP phosphodiesterase and induced aggregation. J Med Chem 1991;34:2906-2916.

41. Mills DCB, Smith JB. The influence on platelet aggregation of drugs that affect the accumulation of adenosine 3,5'-cyclic monophosphate in platelets. Biochem $J$ 1971;121:185-196.

42. Minami M, Driscoll EM, Lucchesi BR. Antithrombotic effects of BMY21190, an inhibitor of cAMP phosphodiesterase, in a canine model of coronary artery thrombosis. Jpn Circ J 1993;57:979-992.

43. Minami M, Driscoll EM, Simpson PJ, Hoff PT, Lucchesi BR. Effects of BMY21190, an inhibitor of cAMP phosphodiesterase, on infarct size and myeloperoxidase activity in the ischemic myocardium of a canine occlusion-reperfusion model. Pharmacology 1994 (in press).

44. Minami M, Driscoll E, Lucchesi BR. Antithrombotic and cardiovascular effects of BMY20844, an inhibitor of cAMP phosphodiesterase, in a canine model of coronary artery thrombosis. Biogenic Amines 1994 (in press).

45. Moschos CB, Lahir K, Lyons M, Weiss AB, Oldewurtel HA, Regan TJ. Relationship of microcirculatory thrombosis to thrombus in the proximal coronary artery: Effect of aspirin, dipyridamole and thrombolysis. Am Heart $J$ 1973;86:61-68.

46. MucPhee CH, Harrison SA, Beavo JA. Immunological identification of the major platelet low-Km cAMP phosphodiesterase: Probable target for antithrombotic agents. Proc Nat Acad Sci USA 1986;83:6660-6663.

47. Mullane KM, Read N, Salmon JA, Moncada S. Role of leukocytes in acute myocardial infarction in anesthetized dogs: Relationship to myocardial salvage by anti inflammatory drugs. $J$ Pharmacol Exp Ther 1984;228(2):510-522.

48. Mullane KM, Kraemer R, Smith B. Myeloperoxidase activity as a quantitative assessment of neutrophil infiltration into ischemic myocardium. J Pharmacol Meth 1985;14:157-167.

49. Muller B, Lugnier C, Stoclet JC. Implication of cyclic AMP in the positive inotropic effects of cyclic GMP-inhibited cyclic AMP phosphodiesterase inhibitors on guinea pig isolated left atria. $J$ Cardiovasc Pharmacol 1990;15:444-451.

50. Olson EM, Kim D, Smith TW, Marsh JD. Mechanisms of the positive inotropic effect of milrinone in cultured embryonic chick ventricular cells. J Mol Cell Cardiol 1987;19:95-104

51. Pattison A, Eason CT, Bonner FW. The in vitro effect of amrinone on thromboxane B2 synthesis in human whole blood. Thromb Res 1986;42:817-824.

52. Rao GHR, Einzig S, Johnson GL, White JG. Effect of amrinone, a cardiotonic drug, on hemodynamics and platelet function. Prostagland Med 1981;6:51-64.

53. Romson JL, Haack DM, Abrams GD, Lucchesi BR. Prevention of occlusive coronary artery thrombosis by prostacyclin infusion in the dog. Circulation 1981;64:906-914.

54. Romson JL, Hook BG, Rigot VH, Schork MA, Swanson DR, Lucchesi BR. The effect of ibuprofen on accumulation of indium-111-labeled platelets and leukocytes in experimental myocardial infarction. Circulation 1982;66:1002-1011.

55. Romson JL, Hook BH, Kunkel SL, Abrams GD, Schork MA, Lucchesi BR. Reduction of the extent of ischemic myocardial injury by neutrophil depletion in the dog. Circulation 1983;67:1016-1023.

56. Ruf W, McNamara JJ, Suehiro G, Wickline SA. Platelet trapping in myocardial infarct in baboons: Therapeutic effect of aspirin. Am J Cardiol 1980;46:405-412.

57. Sabina RL, Kernstine KH, Boyd RL, Holmes EW, Swain JL. Metabolism of 5-amino-4imidazolecarboxamide riboside in cardiac and skeletal muscle. J Biol Chem 1982;257:10178-10183.

58. Salama SE, Haslam RJ. Characterization of the protein kinase activities of human platelet supernatant and particular fractions. Biochem $J$ 1984;218:285-294.

59. Seiler SM, Arnold AJ, Grove RI, Fifer CA, Keely SL Jr, Stanton HC. Effects of anagrelide on platelet cAMP levels, cAMP-dependent proteinkinase and thrombin-induced $\mathrm{Ca}^{2+}$ fluxes. $J$ Pharmacol Exp Ther 1987;243:767-774.

60. Seiler S, Gillespie E, Arnold AJ, Brassard CL, Meanwell NA, Fleming JS. Imidazoquinoline derivatives: 
Potent inhibitors of platelet cAMP phosphodiesterase which elevate cAMP levels and activate protein kinase in platelets. Thromb Res $1991 ; 62: 31-42$.

61. Silver PJ. Biochemical aspects of inhibition of cardiovascular low $(\mathrm{Km})$ cyclic adenosine monophosphate phosphodiesterase. Am J Cardiol 1989;63:2A-8A.

62. Sircar I, Duell BL, Bobowski G, Bristol JA, Evans DB. Cardiotonic agents. 2. Synthesis and structureactivity relationships of 4,5-dihydro-6-[4-(H-imidazol-1-yl) phenyl-3 (2H)-pyridazinones: A new class of positive inotropic agents. $J$ Med Chem 1985;28:1405-1411.

63. Smith EF, Lefer AM, Aharony D, et al. Carbocyclic thromboxane $\mathrm{A}_{2}$ : Aggravation of myocardial ischemia by a new synthetic thromboxane $A_{2}$ analog. Prostaglandins 1981;21:443-456.

64. Sutko JL, Kenyon JL, Reves JP. Effects of amrinone and milrinone on calcium influx into the myocardium. Circulation 1986;73(suppl III):52-58.

65. Tang SS, Frojmovic MM. Inhibition of platelet function by antithrombotic agents which selectively inhibit low-Km cyclic 3' 5' -adenosine monophosphate phosphodiesterase. J Lab Clin Med 1980;95:241-257.

66. Ward A, Brogden RN, Heel RC, Speight TM, Avery GS. Amrinone. A preliminary review of its pharmacological properties and therapeutic use. Drugs 1983;26:468-502.

67. Weishaar RE, Cain MH, Bristol JA. A new generation of phosphodiesterase inhibitors: Multiple molecular forms of phosphodiesterase and the potential for drug selectivety. $J$ Med Chem 1985;28:537-545.

68. Weishaar RE, Burrows SD, Kobylarz DC, Quade MM, Evans DB. Multiple forms of cyclic nucleotide phosphodiesterase in cardiac and smooth muscle and in platelets. Isolation, characterization and effects of various reference phosphodiesterase inhibitors and cardiotonic agent. Biochem Pharmacol 1986;35:787800.

69. Wells JN, Miller JR. Inhibition of cyclic nucleotide phosphodiesterases in muscle. Trend Pharmacol Sci 1983;4:385-387.

70. Werns SW, Shea MJ, Lucchesi BR. Free radicals in ischemic myocardial injury. J Free Radicals in Biol Med 1985; 1:103-110.

71. Werns SW, Shea MJ, Driscoll EM, et al. The independent effects of oxygen radical scavengers on canine infarct size. Circ Res 1985;56:895-898.

72. Werns SW, Lucchesi BR. Free radicals and ischemic tissue injury. Trend Pharmacol Sci 1990;11:161-166.

73. Yamamoto T, Lieberman F, Osborne JC Jr, Manganiello VC, Vaughn M, Hidaka H. Selective inhibition of two soluble adenosine cyclic $3^{\prime}, 5^{\prime}$-phosphate phosphodiesterases partially purified from calf liver. Biochemistry 1984;23:670-675 